\title{
Effects of Variation of Some Process Variables on Recrystallization Rate of Aluminium Alloy (6063)
}

\author{
O.E. Olorunniwo*, P.O. Atanda and K.J. Akinluwade \\ Department of Materials Science and Engineering \\ Obafemi Awolowo University, Ile-Ife. Nigeria. \\ *Correspondence author e-mail:oolorunn@oauife.edu.ng, Phone:+2348069410962
}

\begin{abstract}
Effects of different annealing temperature, holding time and degree of deformation on recrystallization rate of Aluminium alloy (6063) were studied. Fifteen suitably dimensioned samples were prepared from Aluminium alloy (6063). Seven of these were subjected to 70\% cold plastic deformation, seven to $90 \%$ and one left undeformed. All the samples were then subjected to annealing heat treatment to relief deformation-induced stresses. The average values of Yield and Ultimate tensile loads were obtained from three preliminary tensile tests as $121.33 \mathrm{Kgf}$ and 192.67 Kgf respectively. From these, 70 and 90\% deformations were estimated. After a metallographic test on the as-received, the samples were subjected to recrystallization annealing under different conditions of temperature $\left(380^{\circ} \mathrm{C}\right.$ and $\left.450{ }^{\circ} \mathrm{C}\right)$ and holding time $(20,30$ and 40 minutes). Photomicrographs of the heat treated samples were taken from which the number of grains was counted, with the aid of a magnifying lens, from a $1 \mathrm{~cm}^{2}$ area inscribed on their surfaces. The results obtained showed that the higher the degree of cold work, the higher the rate of recrystallization, the higher the nucleation rate and the finer the grains. The higher the holding time at a given recrystallization temperature, the larger the grains due to a longer time available for grain growth. It was also deduced that recrystallization is thermally activated and its rate increases with increase in temperature.
\end{abstract}

Keywords: recrystallization, holding time, plastic deformation, nucleation rate 


\section{INTRODUCTION}

Strain hardening is the phenomenon whereby a ductile metal becomes harder and stronger as it is plastically deformed. It is sometimes called work hardening or cold working because the temperature at which deformation takes place is "cold" relative to the absolute melting temperature of the metal [1]. Hot working on the other hand is a deformation carried out at temperatures higher than $0.6 \mathrm{~T}_{\mathrm{m}}\left(\mathrm{T}_{\mathrm{m}}\right.$ is the melting temperature in Kelvin) and relatively high strain rates $\left(10^{-1}\right.$ to $\left.10^{3} \mathrm{~s}^{-1}\right)[5]$.

Strain hardening or cold working is one of the well known strengthening mechanisms for singlephase metals. It is often convenient to express the degree of plastic deformation as percent cold work. With an increase in percent cold work, steel, brass and copper increase in yield and tensile strength but the price for this enhancement of hardness and strength is in the ductility of the metals [1]. In industries, strain hardening is often utilized on a commercial scale to enhance the mechanical properties of materials during fabrication processes.

After a metal is plastically deformed its microstructure evidently undergoes some alterations. However, the mechanical characteristics and microstructural features of a cold worked metal may be restored to their pre-deformed condition by a suitable heat treatment during which recovery, recrystallization and grain growth occur. The amount of recrystallization is a function of time, temperature, and the degree of prior cold working [2]. The grain size depends upon the temperature of recrystallization annealing, the holding time at this temperature, the degree of previous deformation, the chemical composition of the alloy, the size of the initial grains, the presence of insoluble impurities, etc [4].

Since a number of factors come into play during these processes, many possible outcomes are obtainable. Gorelik (1981) observed that the structure of a deformed (strain hardened) material can change on recrystallization within very wide limits: from a partially recrystallized structure that retains a certain extent the original deformed structure, to a fully recrystallized structure. [2]

Gorelik (op cit) noted that the large diversity of the still unsolved problems in the theory of recrystallization is due to a number of reasons: first, fine details of the dislocation structure of deformed metal, or in essence the initial conditions of recrystallization are still unclear, as are the structures of various types of grain boundary. Without full clarity of this aspect, it is impossible to understand the mechanisms of texture formation, the role of trace impurities, etc. Second, the process of recrystallization, seemingly quite simple, is actually extremely complicated for the mere reason that it is a structure-sensitive process that comes about owing to a non-equilibrium state of the system. Third, recrystallization nuclei differ from the deformed matrix only in lattice distortion, but have the same chemical composition. 
In view of the aforementioned difficulties, Gorelik (op cit) advocated that, the experimental tools for studying recrystallization be diversified and new indirect methods worked out to make appropriate conclusions.[6,7] This study therefore looks at effects of some varied parameters on the rate of recrystallization of Aluminium (6063) alloy. The varied parameters were annealing temperature, holding time and degree of deformation.

\section{MATERIALS AND METHODS}

\subsection{Sample Preparation}

The sample of aluminium alloy 6063 was machined on a turret lathe machine to produce fifteen standard tensile test pieces. All the samples were annealed at $350^{\circ} \mathrm{C}$ to homogenize the microstructure and to eliminate induced stresses due to machining.

Three samples were subjected to preliminary tensile test (cold-deformation). The results obtained are: Test I : Yield load $=120 \mathrm{Kgf}$ and Ultimate tensile load $=190 \mathrm{Kgf}$. Test II: Yield load $=$ $120 \mathrm{Kgf}$ and Ultimate tensile load $=188 \mathrm{Kgf}$. Test III: Yield load $=124 \mathrm{Kgf}$ and Ultimate tensile load $=200$ Kgf.

From these results, the average Yield load and Ultimate tensile load were taken as $121.33 \mathrm{Kgf}$ and 192.67 Kgf respectively.

From the foregoing, a load of $121.33 \mathrm{Kgf}$ corresponds to $100 \%$ cold plastic deformation. By the same reasoning, loads of 134.87 and $173.40 \mathrm{Kgf}$ would produce 70 and $90 \%$ cold plastic deformation respectively. Consequently, seven samples were given $70 \%$ cold plastic deformation, seven $90 \%$ while one was left undeformed. To ensure adequate plastic deformation in the samples, they were deformed with stresses which fall between the average Yield load and the Ultimate tensile load.

\subsection{Heat Treatment}

All the samples were cut through their centres to expose that region of surface for metallographic test. In handling the different groups of specimen which were subjected to recrystallization annealing, a coding scheme was used. The fifteen samples were heat treated according to the following procedure and coding scheme:

(1) One sample: As-received-AR

(2) Two samples: Cold worked only-CW ( 70\%=CW-1, 90\%=CW-2)

(3) Cold worked plus recrystallization annealing-AC

a. Two samples: Held at $380^{\circ} \mathrm{C}$ for 20 minutes

70\%: AC1(20-1)

$90 \%$ AC1(20-2) 
b. Two samples: Held at $380^{\circ} \mathrm{C}$ for 30 minutes

70\%: AC1(30-1)

90\% AC1(30-2)

c. Two samples: Held at $380^{\circ} \mathrm{C}$ for 40 minutes

70\%: AC1(40-1)

90\% AC1(40-2)

d. Two samples: Held at $450^{\circ} \mathrm{C}$ for 20 minutes

70\%: AC2(20-1)

90\% AC2(20-2)

e. Two samples: Held at $450^{\circ} \mathrm{C}$ for 30 minutes

70\%: AC2(30-1)

90\% AC2(30-2)

f. Two samples: Held at $450^{\circ} \mathrm{C}$ for 40 minutes

70\%: AC2(40-1)

$90 \%$ AC2(40-2)

After the heat treatment as described above, the samples were ground on 240, 320, 400 and 600 grit emery papers. They were then polished to mirror finish and etched with ${ }^{1}$ Keller's reagent.

\subsection{Point Counting}

This was done to count the number of grains per $1 \mathrm{~cm}^{2}$ area. The formula is $[8,9,10]$ :

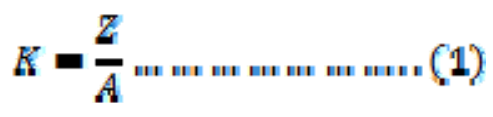

and

$$
Z=M+1 / 2(x)+1 \ldots \ldots . . . . . . . . .(2)
$$

Where $\mathrm{K}$ is number of grains per unit area, $\mathrm{Z}$ is total number of grains in the entire $1 \mathrm{~cm}^{2}, \mathrm{n}$ is number of grains intersected by the edges and not corners of the inscribed square, A equals $1 \mathrm{~cm}^{2}$.

The area A was inscribed on each micrograph and the number of grains within the area was counted with the application of equations (1) and (2) above. The grains were made visible with the use of a magnifying glass. In effect, the number of grains per unit area represents the rate of nucleation.

\section{RESULTS AND DISCUSSION}

Results of counts obtained for all fifteen samples are as presented in Tables 1 and 2. The micrographs obtained at $100 \mathrm{X}$ are as presented in Plates $1-4$, while graphical variations of recrystallization rate (grain count) with holding time are presented in Figures 1-4.

\footnotetext{
${ }^{1}$ The composition is Hydrofluoric acid: 1cm3, Hydrochloric acid: $1.5 \mathrm{~cm} 3$, Nitric acid: $2.5 \mathrm{~cm} 3$ and water: $95 \mathrm{~cm} 3$
} 
Table 1. Interpretation of codes and grain count.

\begin{tabular}{|c|c|c|}
\hline code & Explanation & $\begin{array}{c}\text { Grain } \\
\text { count }\end{array}$ \\
\hline $\mathrm{CW}-1$ & $\begin{array}{c}70 \% \text { deformation, cold worked only } \\
\text { CW-2 }\end{array}$ & 219 \\
& $90 \%$ deformation, cold worked only & 232 \\
$\mathrm{AC} 1(20-1)$ & $70 \%$ deformation, $380^{\circ} \mathrm{C}, 20 \mathrm{~min}$ & 179 \\
$\mathrm{AC} 1(30-1)$ & $70 \%$ deformation, $380^{\circ} \mathrm{C}, 30 \mathrm{~min}$ & 171 \\
$\mathrm{AC} 1(40-1)$ & $70 \%$ deformation, $380^{\circ} \mathrm{C}, 40 \mathrm{~min}$ & 167 \\
& & \\
$\mathrm{AC} 1(20-2)$ & $90 \%$ deformation, $380^{\circ} \mathrm{C}, 20 \mathrm{~min}$ & 200 \\
$\mathrm{AC} 1(30-2)$ & $90 \%$ deformation, $380^{\circ} \mathrm{C}, 30 \mathrm{~min}$ & 184 \\
$\mathrm{AC} 1(40-2)$ & $90 \%$ deformation, $380^{\circ} \mathrm{C}, 40 \mathrm{~min}$ & 180 \\
& & \\
$\mathrm{AC} 2(20-1)$ & $70 \%$ deformation, $450^{\circ} \mathrm{C}, 20 \mathrm{~min}$ & 143 \\
$\mathrm{AC} 2(30-1)$ & $70 \%$ deformation, $450^{\circ} \mathrm{C}, 30 \mathrm{~min}$ & 135 \\
$\mathrm{AC} 2(40-1)$ & $70 \%$ deformation, $450^{\circ} \mathrm{C}, 40 \mathrm{~min}$ & 131 \\
& & \\
$\mathrm{AC} 2(20-2)$ & $90 \%$ deformation, $450^{\circ} \mathrm{C}, 20 \mathrm{~min}$ & 161 \\
$\mathrm{AC} 2(30-2)$ & $90 \%$ deformation, $450^{\circ} \mathrm{C}, 30 \mathrm{~min}$ & 153 \\
$\mathrm{AC} 2(40-2)$ & $90 \%$ deformation, $450^{\circ} \mathrm{C}, 40 \mathrm{~min}$ & 149 \\
\hline
\end{tabular}

Table 2. Recrystallization (grain count) as a function of \% cold deformation, annealing temperature and holding time.

\begin{tabular}{|c|c|c|c|c|}
\hline Code & $\begin{array}{l}\text { \% } \\
\text { Deformation }\end{array}$ & $\begin{array}{l}\text { annealing } \\
\text { temperature }\end{array}$ & $\begin{array}{l}\text { Holding } \\
\text { Time }\end{array}$ & $\begin{array}{l}\text { Grain } \\
\text { Count }\end{array}$ \\
\hline CW-1 & 70 & & & 219 \\
CW-2 & 90 & & & 232 \\
AC1(20-1) & 70 & 380 & 20 & 179 \\
AC1(30-1) & 70 & 380 & 30 & 171 \\
AC1(40-1) & 70 & 380 & 40 & 167 \\
& & & & \\
AC1(20-2) & 90 & 380 & 20 & 200 \\
AC1(30-2) & 90 & 380 & 30 & 184 \\
AC1(40-2) & 90 & 380 & 40 & 180 \\
& & & & \\
AC2(20-1) & 70 & 450 & 20 & 143 \\
AC2(30-1) & 70 & 450 & 30 & 135 \\
AC2(40-1) & 70 & 450 & 40 & 131 \\
& & & & \\
AC2(20-2) & 90 & 450 & 20 & 161 \\
AC2(30-2) & 90 & 450 & 30 & 153 \\
AC2(40-2) & 90 & 450 & 40 & 149 \\
\hline
\end{tabular}




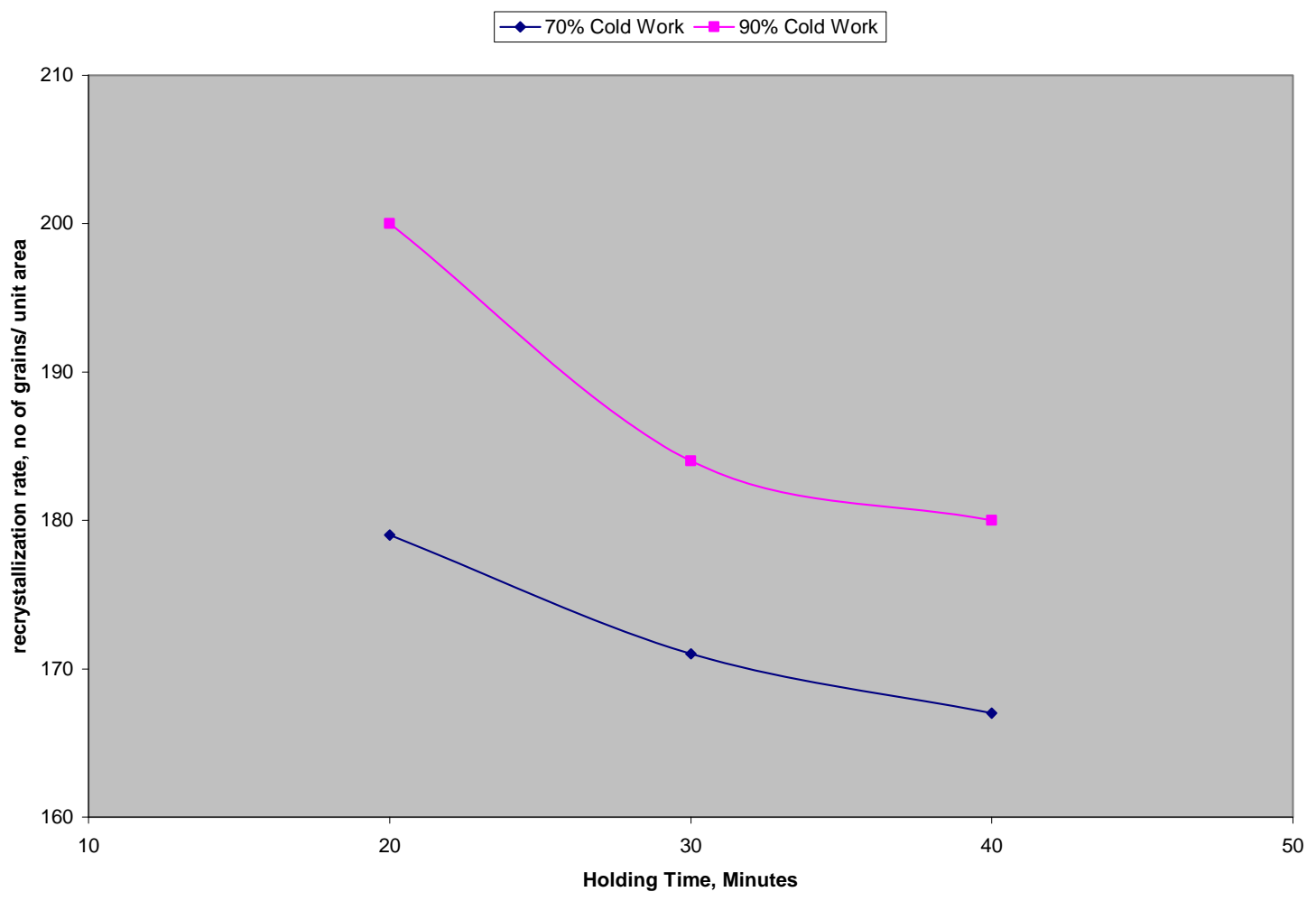

Figure 1. Effect of holding time on recrystallization rate at constant temperature $\left(380^{\circ} \mathrm{C}\right)$.

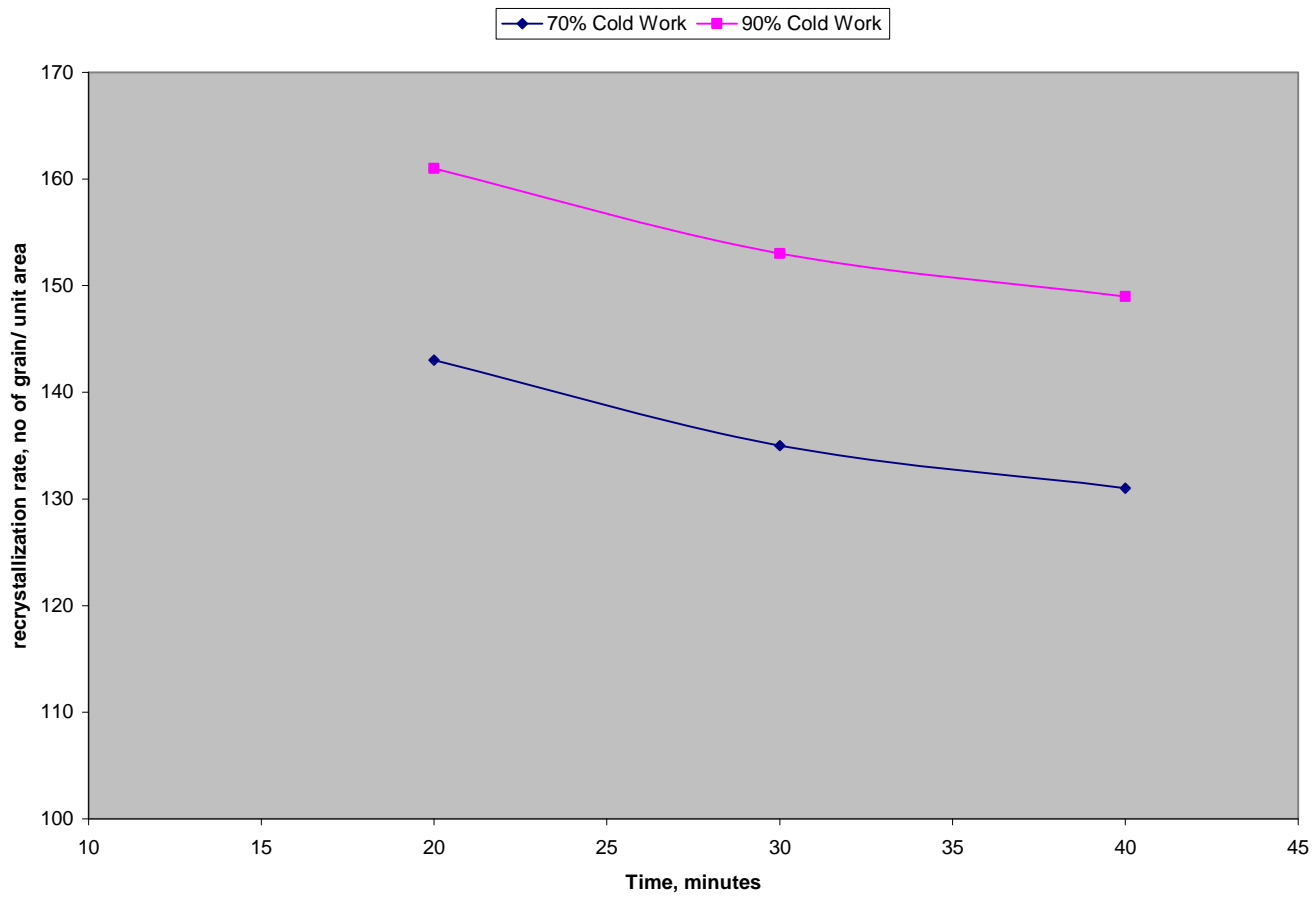

Figure 2. Effect of holding time on recrystallization rate at constant temperature $\left(450^{\circ} \mathrm{C}\right)$. 


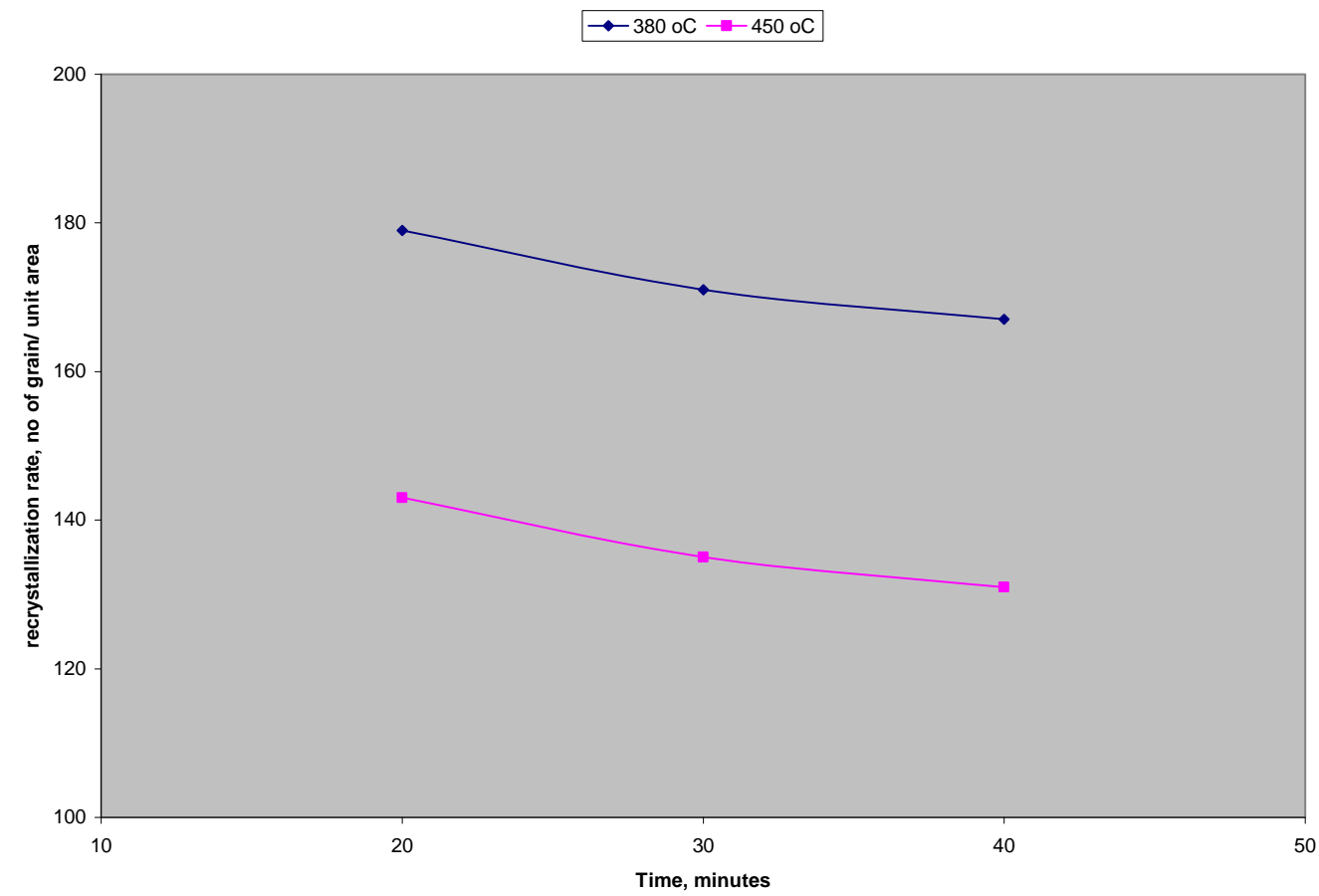

Figure 3. Effect of holding time on recrystallization rate at constant \%cold deformation $(70 \%)$

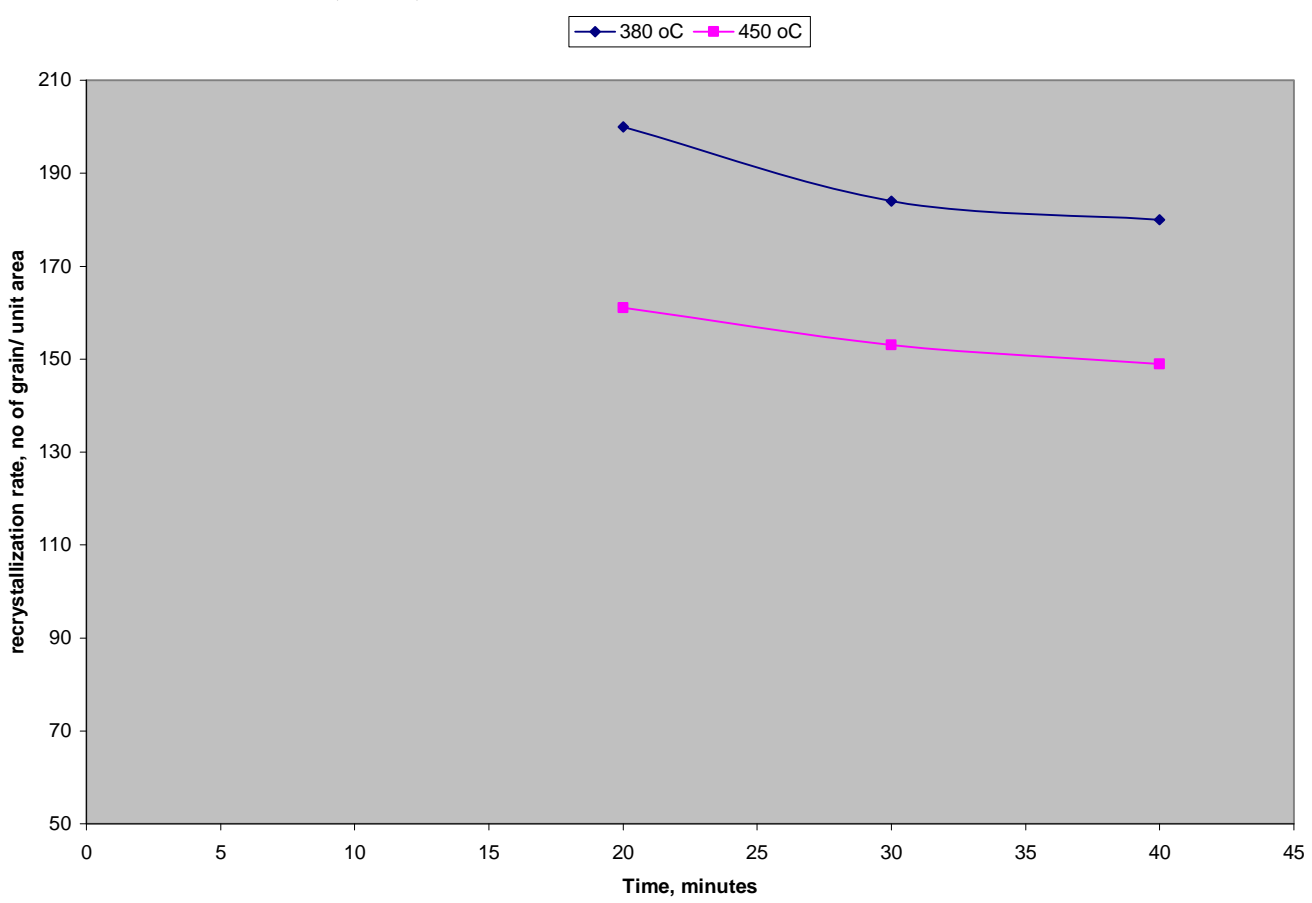

Figure 4. Effect of holding time on recrystallization rate at constant \%cold deformation (90\%). 


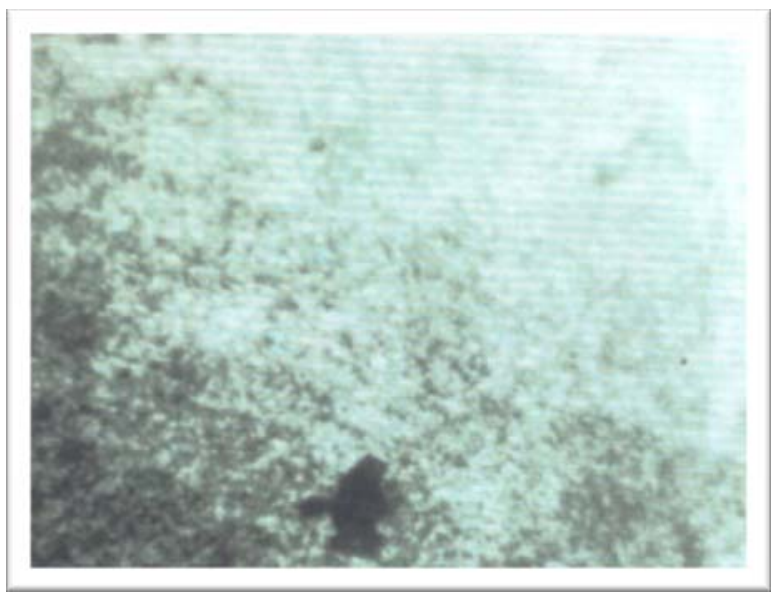

Plate1. As-received

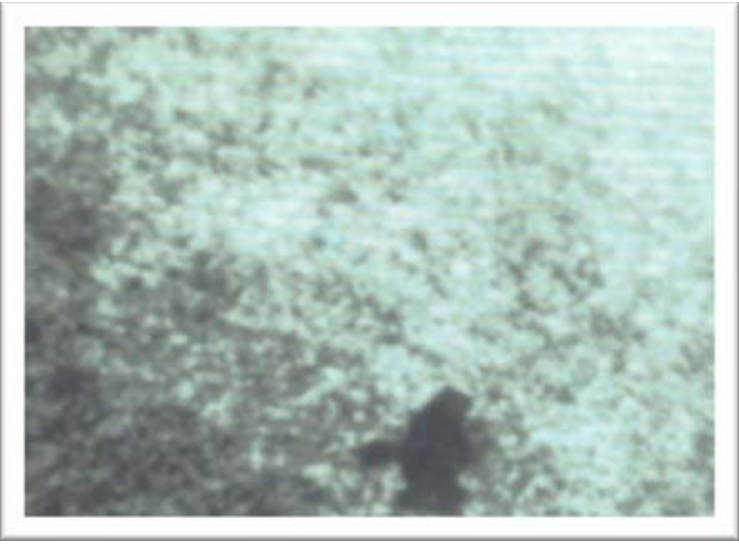

Plate2. $70 \%$ deformation, cold worked only

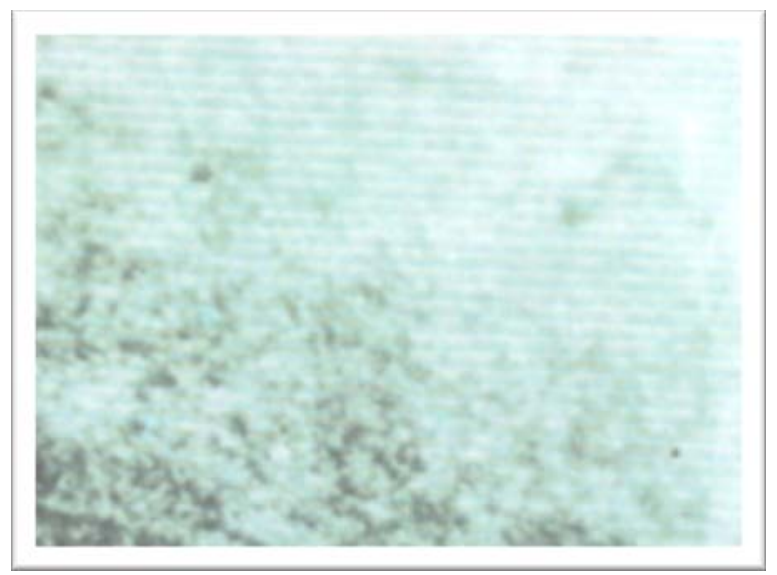

Plate3. 90\% deformation, cold worked only 


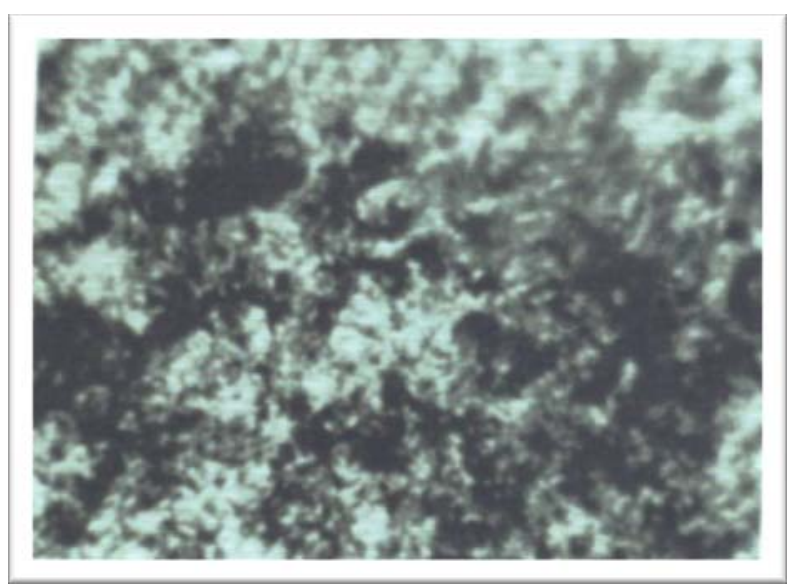

Plate 4. $70 \%$ Deformation, $380^{\circ} \mathrm{C}$, $20 \mathrm{~min}$

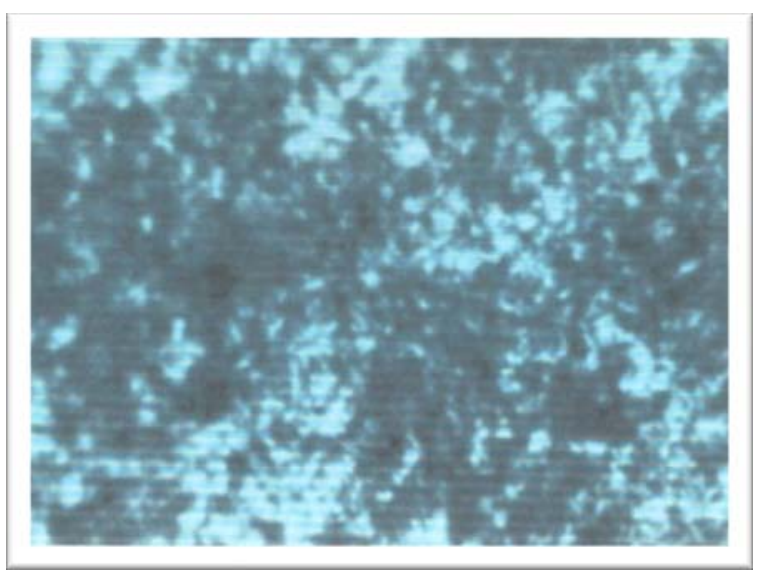

Plate 5. 70\% Deformation, $380^{\circ} \mathrm{C}$, $30 \mathrm{~min}$

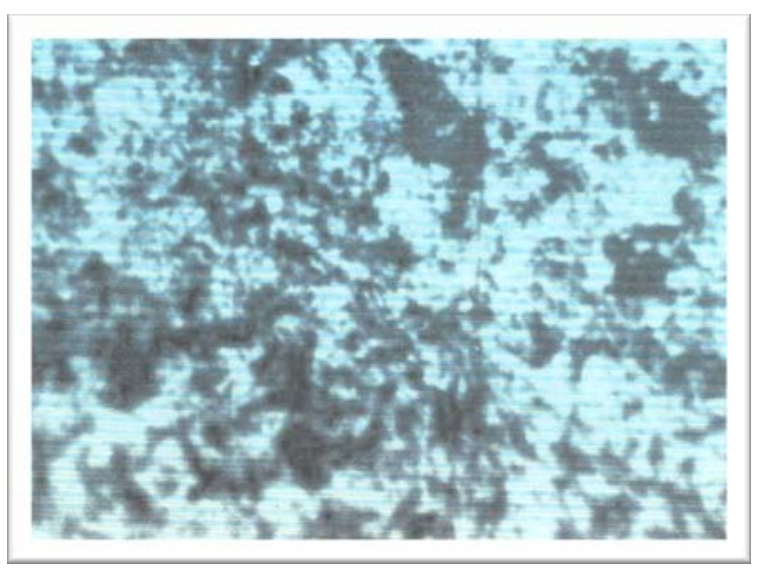

Plate 6. $70 \%$ Deformation, $380^{\circ} \mathrm{C}$, $40 \mathrm{~min}$ 


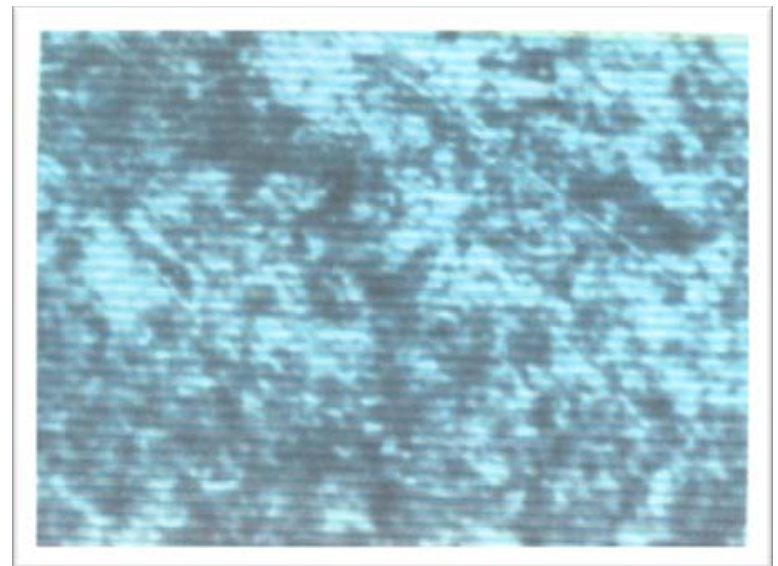

Plate 7. 90\% Deformation, $380^{\circ} \mathrm{C}, 20 \mathrm{~min}$

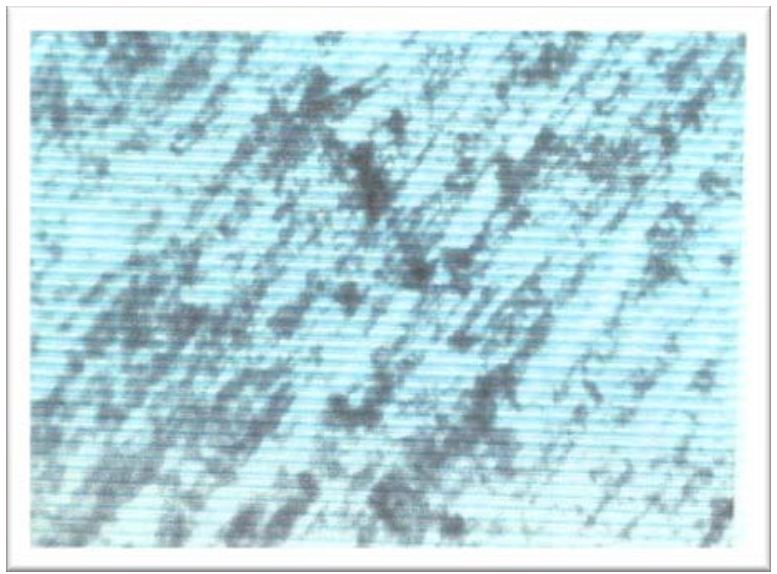

Plate8. 90\% Deformation, $380^{\circ} \mathrm{C}$, 30min

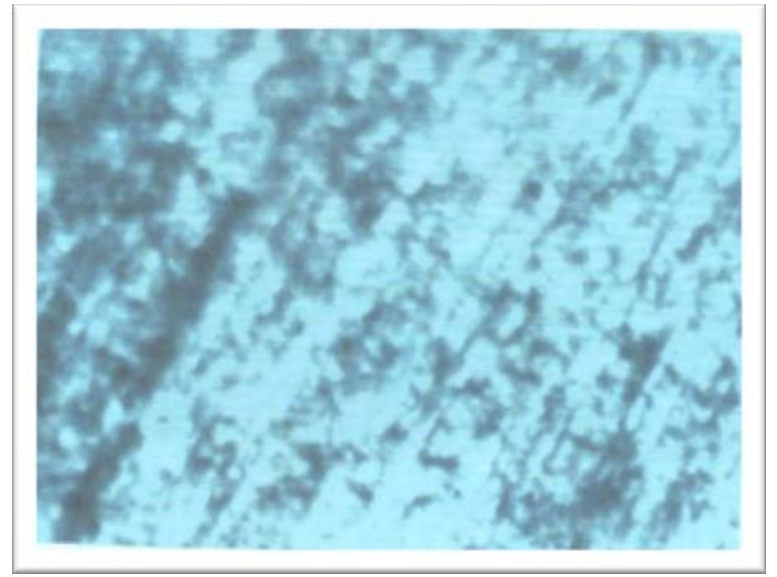

Plate9. 90\% Deformation, $380^{\circ} \mathrm{C}$, $40 \mathrm{~min}$ 


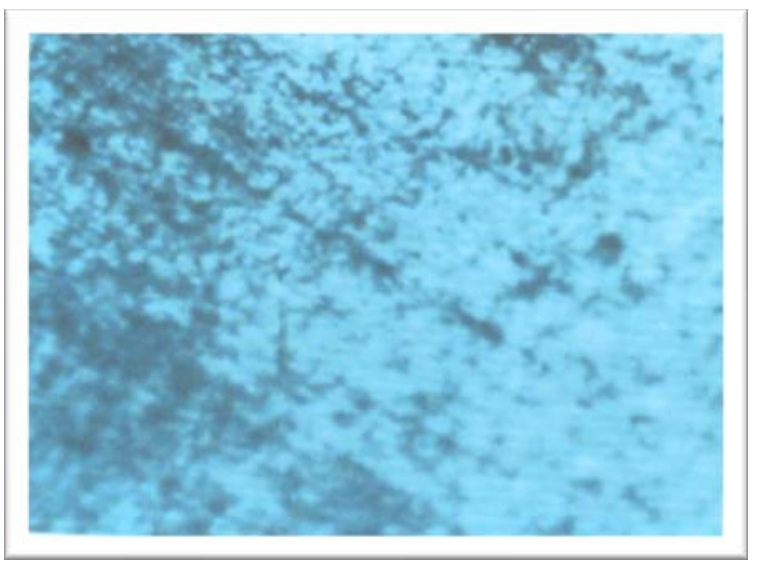

Plate10. 90\% Deformation, $450^{\circ} \mathrm{C}, 20 \mathrm{~min}$

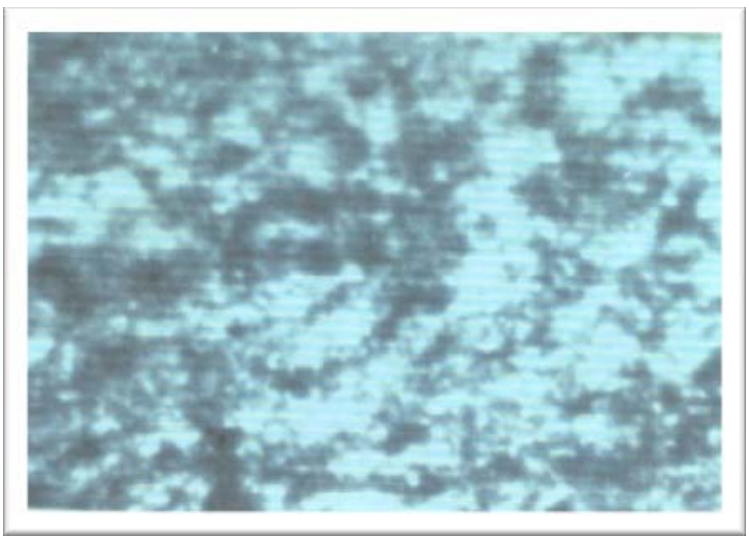

Plate11. $70 \%$ Deformation, $450^{\circ} \mathrm{C}, 30 \mathrm{~min}$

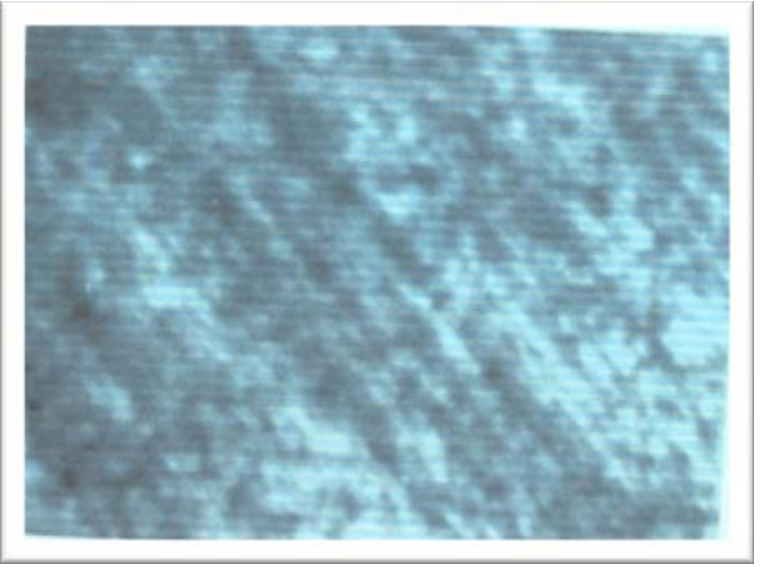

Plate12. $70 \%$ Deformation, $450^{\circ} \mathrm{C}, 40 \mathrm{~min}$ 


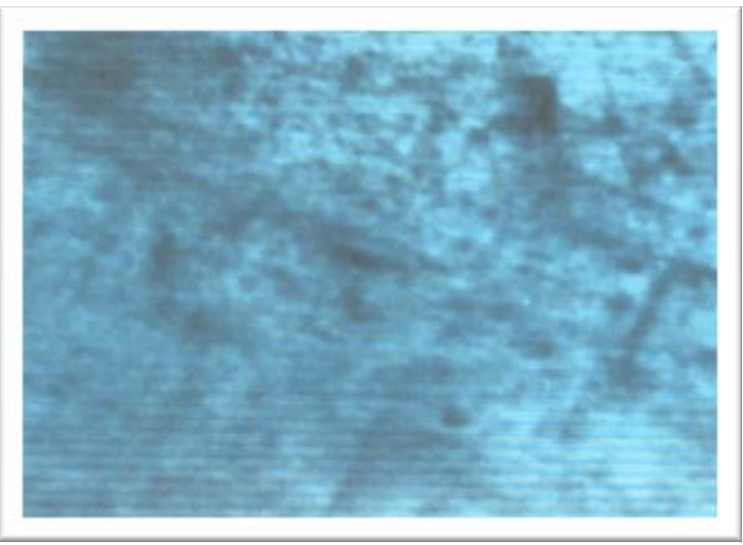

Plate13. 90\% Deformation, $450^{\circ} \mathrm{C}$, $20 \mathrm{~min}$

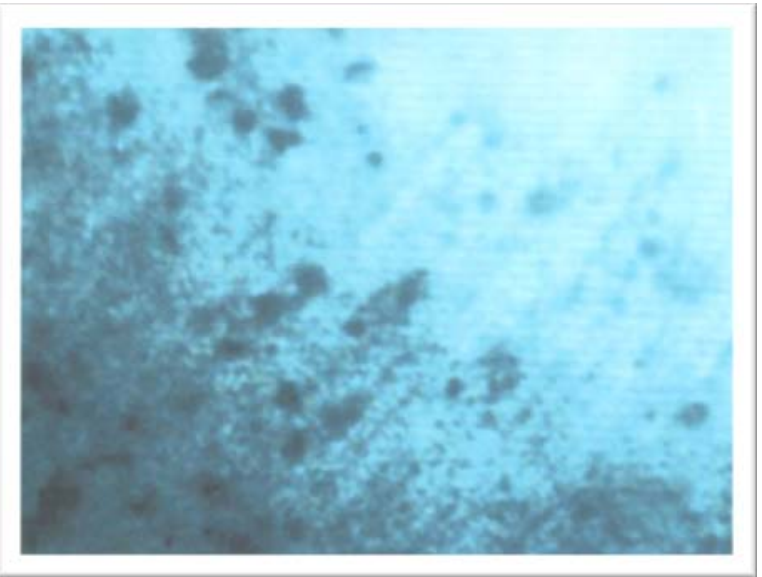

Plate14. 90\% Deformation, $450^{\circ} \mathrm{C}, 30 \mathrm{~min}$

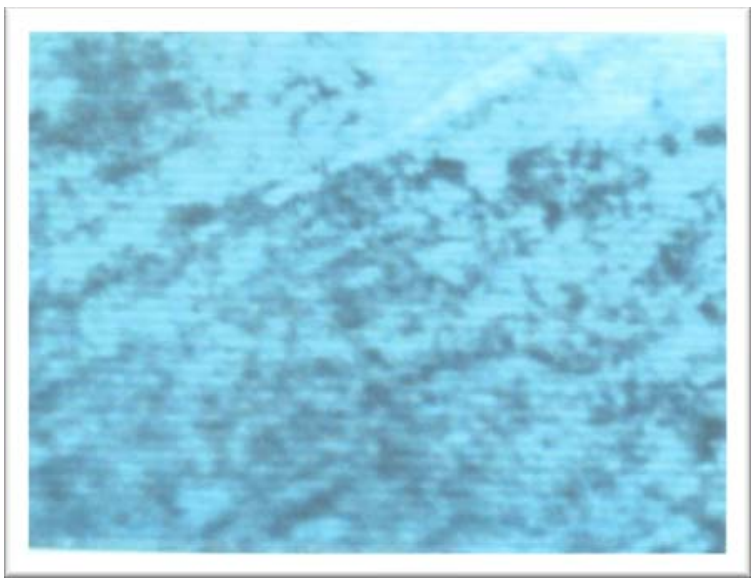

Plate15. 90\% Deformation, $450^{\circ} \mathrm{C}$, $40 \mathrm{~min}$ 


\subsection{Temperature and Recrystallization}

From the analysis of the micrographs, it was found that recrystallization temperature affected the rate of crystallization. The trend observed is: the higher the temperature, the higher the recrystallization rate.

\section{2. \% Cold Deformation and Grain Size}

The new grains formed during nucleation had undistorted lattice with equiaxed grains when compared with that of samples which were only cold worked (CW-1 and CW-2). Mechanical properties of a material are significantly affected by the size of its grains. In general, the finer the grains, the better the mechanical properties.

\subsection{Effect of Holding Time}

It was observed from the experiment that an increase in holding time results in a decrease in number of grains. However, the grains are larger with increased holding time. For instance, sample AC1(40-1) which was soaked at $380^{\circ} \mathrm{C}$ in the furnace for 40 minutes was observed to have lesser grains count but bigger grains size than sample AC1(30-1) that was soaked at same temperature but for 30 minutes.

\subsection{Deformation, Grain Count and Grain Size}

It was observed that the higher the degree of deformation, the finer the grain size. This accounts for the observed increases in total counts per unit area for the samples having higher degree/percent of deformation. For instance, sample AC2(40-1) which was given $70 \%$ cold plastic deformation and annealed at $450^{\circ} \mathrm{C}$ had fewer number of grains per $\mathrm{cm}^{2}$ and larger grain size than sample AC2(40-2) that was given $90 \%$ cold deformation, annealed at same temperature and for same duration.

\section{CONCLUSION}

The following conclusion were drawn from the experiment

1. The higher the degree of cold work, the higher the rate of recrystallization

2. The higher the degree of cold work, the higher the nucleation rate and the finer the grains.

3. The smaller the grain size, the higher the number of grain counts.

4. The higher the holding time at a given recrystallization temperature, the larger the grains due to a longer time available for grain growth. 
5. Recrystallization is thermally activated and its rate increases with increase in temperature.

\section{REFERENCES}

[1] Callister, Jr. W. D. (1997). Materials Science and Engineering: An Introduction, John Wiley \& Sons, Inc. New York.

[2] Gorelik, S. S. (1981). Recrystallization in Metals and Alloys. MIR Publishers Moscow. Translated and revised from the $1978\left(2^{\text {nd }}\right)$ Russian Edition by Afanasyev, V.

[3] Linderberg, R. A. (1981). Processes and Materials of Manufacture. $2^{\text {nd }}$ Edition. Allyn and Bacon, Inc., Massachuesetts.

[4] Lakhtin, Y. (1979). Engineering Physical Metallurgy and Heat Treatment. MIR Publishers Moscow. Translated and revised from the 1977 Russian Edition by Nicholas Weinstein.

[5] Sparlin, L. G. M. (1983). The Evaluation of Load and Torque in Hot Flat Rolling from Slipline Field. Proc. Instn. Mech. Engrs., 197A,277-285.

[6] Rollason, E. C. (1973). Metallurgy for Engineers, Edward Arnold Publishers.London.

[7] Sowole, O. O. Effects of Cold work on the Recrystallization kinetics of Brass. Unpublished B. Sc. Thesis of Obafemi Awolowo University, OAU. IleIfe(1981).pp46-50

[8] Weinberg,F. (1970). Tools and Techniques in Physical Metallurgy. Marcel Dekker, Inc.New York.1970.

[9] Rys,J. Quantitative Metallography, Krakow. 1982.

[10] Pickering,F.B.(1976) The Basis of Quantitative Metallography. Metals and Metallurgy Trust for the Institute of Metallurgical Technicians,London United Kingdom. 